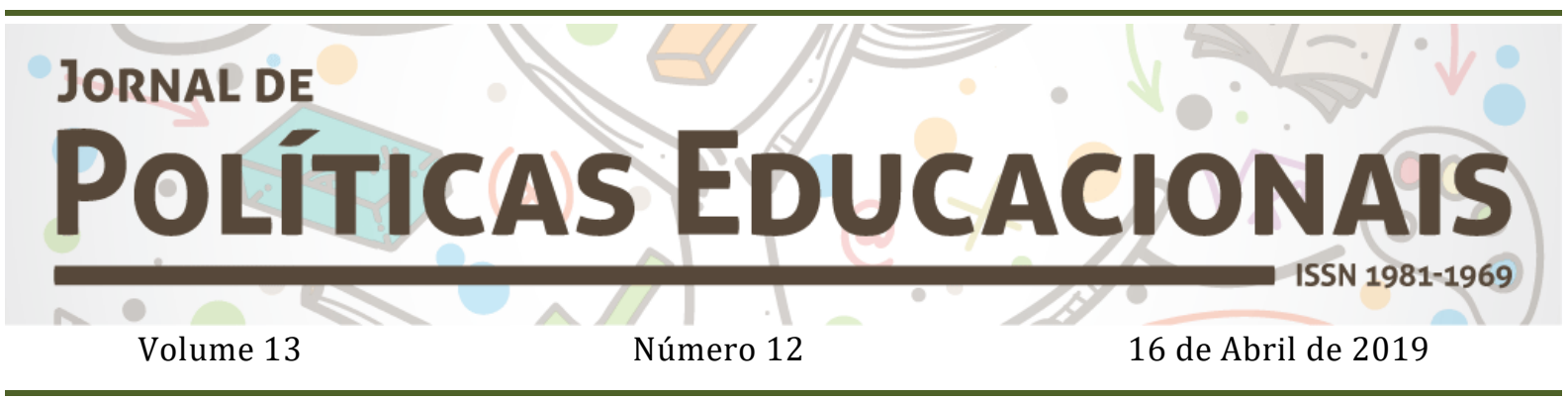

\title{
Democratização da gestão escolar no estado do Tocantins: uma análise crítica do Programa Escola Comunitária de Gestão Compartilhada
}

\section{Democratization of the School Management in the State of Tocantins: a critical analysis of the Community School Program of shared management}

\section{Democratización de la gestión escolar en el Estado de Tocantins: un análisis crítico del Programa Escuela Comunitaria de Gestión Compartida}

Citação: SILVA, R. B. da; DIAS DA SILVA, R. M. Democratização da gestão escolar no Estado do Tocantins: uma análise crítica do Programa Escola Comunitária de Gestão Compartilhada. Jornal de Políticas Educacionais. V. 13, n. 12. Abril de 2019.

http://10.5380/jpe.v13i0.62299

Resumo: 0 artigo visa examinar o Programa Escola Comunitária de Gestão Compartilhada e suas possibilidades de democratização das políticas e da gestão da educação pública no estado do Tocantins. Considerando a situação desse programa, metodologicamente cotejada a partir de um estudo documental, reflete acerca do alcance e das possibilidades de democratização em jogo nas políticas, na gestão e nas políticas de gestão da Educação Básica implementadas. Nesse contexto, constatou-se que a aferição dos resultados opera pela classificação das escolas e, de forma desigual, determina o nível de recursos e benefícios a serem recebidos. Além disso, em se tratando de baixo rendimento, há uma tendência de culpabilização da própria escola e de seus atores. Conclui-se haver uma ambivalência entre a propagação de uma cultura da responsabilização, chamada de "rede de responsabilidade", e a efetivação de uma gestão

\footnotetext{
${ }^{1}$ Mestranda em Educação pelo Programa de Pós-Graduação em Educação da Universidade do Vale do Rio dos Sinos. E-mail: silvarafaelabrito@gmail.com

${ }^{2}$ Professor da Escola de Humanidades e do Programa de Pós-Graduação em Educação da Universidade do Vale do Rio dos Sinos. Doutor em Ciências Sociais. E-mail: rodrigods@unisinos.br
} 
democrática, interpretada enquanto ação coletiva que precisa ser vivenciada continuamente por meio do aprendizado da democracia. Tal ambivalência evidencia a pertinência de problematizações acerca das definições de democracia no bojo dessa política.

Palavras-chave: Democratização. Gestão Escolar. Descentralização. Autonomia.

Abstract: This article aims to examine the Community School of Shared Management Program and its possibilities of policies and management of public education democratization in the State of Tocantins, Brazil. Considering the situation of this program, methodologically collated from a documentary study, it reflects on the scope and possibilities of democratization at play in the policies, management and policies of Basic Education implemented. In this context, it was verified that the measurement of results operates by the classification of schools and, unequally, determines the level of resources and benefits to be received. In addition, in the case of low income, there is the blame of the school itself and its actors. We conclude that there is an ambivalence between the propagation of a culture of accountability, called a "network of responsibility", and the implementation of a democratic management, interpreted as collective action that must be experienced continuously through the learning of democracy. Such ambivalence highlights the pertinence of problematizations about the definitions of democracy in the context of this policy.

Keywords: Democratization. School management. Decentralization. Autonomy.

\section{Resumen}

El artículo busca examinar el Programa Escuela Comunitaria de Gestión Compartida y sus posibilidades de democratización de las políticas y de la gestión de la educación pública, en el Estado de Tocantins. Considerando la situación de este programa, metodológicamente cotejada a partir de un estudio documental, refleja el alcance y las posibilidades de democratización en juego en las políticas, en la gestión y en las políticas de gestión de la Educación Básica implementadas. En ese contexto, se constató que la evaluación de los resultados opera por la clasificación de las escuelas y, de forma desigual, determina el nivel de recursos y beneficios a ser recibidos. Además, en el trato de bajo rendimiento, hay una tendencia de culpabilización de la propia escuela y de sus actores. Se concluye que hay una ambivalencia entre la propagación de una cultura de la responsabilización, llamada "red de responsabilidad", y la efectividad de una gestión democrática, interpretada como una acción colectiva que necesita ser vivenciada continuamente a través del aprendizaje de la democracia. Tal ambivalencia pone de manifiesto la pertinencia de las problemáticas sobre las definiciones de democracia en el seno de esta política.

Palabras clave: Democratización. Gestión Escolar. Descentralización. Autonomía.

\section{Introdução}

No presente artigo, pretendemos examinar o Programa Escola Comunitária de Gestão Compartilhada e suas possibilidades de democratização das políticas e da gestão da educação pública no estado do Tocantins. A partir da situação desse programa, refletiremos acerca do alcance e das possibilidades de democratização em jogo nas políticas, na gestão e nas políticas de gestão da Educação Básica implementadas no referido contexto.

A literatura publicada na área de Políticas Educacionais, nas últimas duas décadas principalmente, tem enfatizado as influências exercidas pelos organismos e agências internacionais sobre a educação pública e, mais especificamente, a gestão escolar (AFONSO, 2001; DALE, 2004; LIBÂNEO, 2012). Contudo nos importa também refletir 
SILVA, R. B. da; DIAS DA SILVA, R. M. Democratização da gestão escolar no Estado do Tocantins: uma análise crítica do Programa Escola Comunitária de Gestão Compartilhada

sobre como ocorrem tais influências, seus mecanismos de controle e, com efeito, os modos pelos quais as escolas se posicionam frente ao conjunto dessas demandas. No horizonte dessas produções intelectuais, ainda que expresso de modos distintos, a escola contemporânea tem sido descrita a partir de um conjunto de discursividades e preceitos político-institucionais que a configuram como uma "organização flexível”, sob os quais ela é responsabilizada pela difusão de princípios como descentralização, autonomia, participação e, inclusive, gestão democrática.

Em condições históricas contraditórias, a educação escolar é situada socialmente em uma condição de ambivalência (por vezes, muito mais de paradoxo), entre as garantias de um direito público e social configurado desde processos de gestão democrática em sua organização política até outros modelos de gestão fundamentados em racionalidades da métrica, das medidas focalizadas ou focalizadoras e dos resultados econômico-políticos. Tais processos ora acentuam um compromisso político com a garantia e a defesa do acesso e permanência (com êxito) de todos os estudantes na escola, ora explicitamente se vê esvaziada dos imprescindíveis investimentos e da adequada alocação de recursos para seu funcionamento. Não obstante, há diversos processos de tomada de decisão, com um claro direcionamento formal para decisões que envolvam as comunidades e os atores escolares, nem sempre correspondendo a uma perspectiva democrática. Ainda que suas concepções de democracia careçam de exame, há nas instituições escolares um conjunto de procedimentos e práticas de gestão que envolvem os pais e familiares, sob a forma de associações de apoio escolar.

Cada uma dessas formas de apoio escolar estabelece relações próprias e peculiares com o Estado. No estado do Tocantins, a gestão da educação é realizada por meio do Programa Escola Comunitária de Gestão Compartilhada (PECGC), que busca, de acordo com seu documento oficial vigente, "democratizar a gestão educacional, visando dar agilidade e autonomia para elaborar, implementar e fortalecer o Projeto Político Pedagógico, em conformidade com a realidade e as necessidades de cada unidade escolar" (TOCANTINS, 2017, p. 6). Nessa perspectiva, produzimos o presente artigo com a finalidade de examinarmos a seguinte indagação: em que medida o Programa Escola Comunitária de Gestão Compartilhada contribui para a democratização da educação no Tocantins? 
Nossa intenção, portanto, é oferecer subsídios para uma análise sobre o Programa Escola Comunitária de Gestão Compartilhada, política estadual de gestão da educação básica no estado do Tocantins, por meio de análise crítica dos pressupostos de democratização da gestão escolar anunciados em seus documentos oficiais. Importounos, nessa elaboração, conhecer a concepção e a trajetória histórico-social de implantação e implementação do PECGC no estado entre os anos de 1997 a 2017; assim como analisar e identificar seus pressupostos e objetivos sociais e políticos.

Metodologicamente, desenvolvemos essa análise crítica em duas frentes de trabalho. Primeiramente, produzimos uma revisão bibliográfica, a qual se caracterizou pela consulta e estudo sistematizado da produção intelectual disponível acerca das temáticas em estudo. Em seguida, como estratégia metodológica principal, realizamos uma análise documental, a partir de um levantamento e seleção de documentos institucionais que regem e orientam o Programa Escola Comunitária de Gestão Compartilhada. 0 que nos possibilitou, de acordo com Ludke e André (1986), estudar e analisar esses documentos extraindo informações relevantes, contextualizando-as e relacionando-as à questão norteadora desta elaboração.

\section{A escola como uma “organização flexível”: uma abordagem diagnóstica}

As reformas educacionais promovidas nos mandatos presidenciais de Fernando Henrique Cardoso (1995 a 2002) foram resultantes de um extenso processo de reestruturação produtiva do sistema econômico brasileiro, o qual pode ser caracterizado pela passagem de um modelo taylorista/fordista, com uma significativa mudança no capitalismo, para um modelo toyotista de produção flexível, em face à ascensão de formas econômicas neoliberais (LIBÂNEO, 2012). O contexto dessas mudanças no plano da produção operou influências sobre as concepções de Estado e de políticas públicas, reestruturando-as a partir de um modelo gerencial. Esses processos engendraram uma internacionalização da economia, a centralização do capital e um conjunto de redefinições institucionais orientadas para o mercado e ao empresariamento.

Para a composição dessa seção diagnóstica, alusiva ao campo escolar, importa considerarmos que houve uma mudança no sentido e no emprego do termo administração para, agora, gestão. Paro (1996, 2001), Cury $(1997,2002)$ e Barroso $(2001)$ sinalizam que 
SILVA, R. B. da; DIAS DA SILVA, R. M. Democratização da gestão escolar no Estado do Tocantins: uma análise crítica do Programa Escola Comunitária de Gestão Compartilhada

as características que cada palavra carrega em seus significados e sentidos no campo educacional não são aleatórias, cabendo-nos, como atores nesse campo, reconhecer o contexto histórico, social e cultural a que se aplicam e como se originam.

Drabach e Mousquer (2009), em investigação sobre produções intelectuais em administração e gestão escolar, evidenciaram que, nos fundamentos da ideia de gestão democrática, há princípios do sistema de produção toyotista, a saber: flexibilização, trabalho em equipe, participação, autogestão, termos esses que têm influenciado a organização da educação brasileira. Para as autoras,

A desejada Gestão Democrática do Ensino Público surge multifacetada. De um lado, guardadora de um projeto democrático com vistas à ampliação dos espaços de cidadania e construção de uma educação de qualidade, de outro, como estratégia do gerencialismo econômico global no fortalecimento do sistema capitalista de sociedade. (DRABACH; MOUSQUER, 2009, p. 279).

Na transição linguística do uso do termo administração para gestão, as autoras enfatizam os limites e as contradições das políticas públicas para a educação. Há, por assim dizer, uma espécie de embate entre a gestão democrática e a gestão gerencial. Uma duplicidade que, no terreno em que se efetiva a gestão educacional, a escola acaba por predominar seu sentido de ferramenta de controle. Substancialmente, as proposições do New Public Management e Reinventing Government ${ }^{3}$ elencam estratégias que configuram a influência da gestão gerencial na educação. Nesse sentido, Stephen Ball (2014) elucida como somos "reformados" pelo neoliberalismo, ao modo que este, na forma de mercado, promove a "mercantilização da prática educacional - por exemplo, nas economias de valor aluno, por meio de remuneração por desempenho, gestão de desempenho e flexibilização e substituição do trabalho" (BALL, 2014, p. 64), cujo processo desenvolvese e materializa-se nas práticas de gestão do gerencialismo.

Para o novo gerente da educação, uma boa administração envolve implementação tranquila e eficiente de objetivos situados fora da escola, dentro dos limites também estabelecidos fora da escola. Não é papel do gerente questionar ou criticar esses objetivos e limites. 0 discurso do novo gerencialismo na educação enfatiza propósitos instrumentais de escolarização - aumentando padrões e desempenho conforme mensurados pela avaliação dos resultados, nível de frequência e destino dos egressos - e está frequentemente articulado a

\footnotetext{
${ }^{3}$ A esse respeito, ver Carvalho (2009).
} 
SILVA, R. B. da; DIAS DA SILVA, R. M. Democratização da gestão escolar no Estado do

Tocantins: uma análise crítica do Programa Escola Comunitária de Gestão Compartilhada

um vocabulário da empresa, excelência, qualidade e eficiência (GEWIRTZ; BALL, 2006, p.199).

Trata-se, portanto, de potencializar nos professores e nos alunos um espírito empreendedor, cuja atuação circunscreve-se às bases da competitividade, do poder e do individualismo, em detrimento do discurso de gestão democrática que valorizaria a coletividade, a responsabilização pelos resultados e pelo bem-estar da instituição.

Barroso, em importante estudo, apresenta-nos outros elementos reflexivos:

\begin{abstract}
Ao falarmos do sistema educativo poder-se-á utilizar o termo "administração" para referir as atividades (planificação, organização, direcção, controlo) que têm em vista assegurar o funcionamento do sistema em seu conjunto, e "gestão" para significar essas mesmas atividades ao nível de cada escola, ou instituição. Ao falarmos de uma escola em particular, enquanto organização, podemos utilizar o termo "administração" para significar o processo de definição das metas e das políticas que vão orientar o funcionamento da escola (quer no quadro da reinterpretação do normativo legal, quer no quadro de suas autonomias) e "gestão" para significar o processo de optimização dos recursos humanos, materiais e financeiros que vão permitir concretizar esses objectivos e essas políticas (BARROSO, 2001, p. 11).
\end{abstract}

Nessa perspectiva, considerando a escola como uma organização, analisaremos a política e a gestão educacional implementada no estado do Tocantins, interpelando-nos acerca da ideia de gestão democrática. Em nome da democratização, muitas vezes as políticas educacionais colocam a escola como um produto à disposição dos empresários (privatização) e de um conjunto cada vez mais amplo de atores públicos e privados. De acordo com Carvalho,

o discurso que conclama à democratização, identificada com a defesa dos interesses privados e com o ideal de auto-governo, abre caminho para práticas privatizadoras e para a realização dos interesses privados, criando novos conteúdos políticos, compatíveis com os novos interesses econômicos e políticos (flexibilização, desregulamentação, aumento da concorrência, maior responsabilização da sociedade), dos quais emana uma nova concepção de democracia participativa e de cidadania. Esta, despojada do seu conteúdo tradicional, ou seja, da garantia de direitos sociais, das políticas sociais compensatórias e do foco na melhoria da distribuição de renda, reafirma os princípios do liberalismo clássico de auto-gestão, auto-organização, liberdades individuais. (CARVALHO, 2008, p.265 grifos nossos).

Como então conceber democracia reafirmando princípios do liberalismo econômico, no qual o individualismo se sobrepõe ao coletivo? Do ponto de vista investigativo, vemos, então, embates, contradições e limites postos em práticas ditas 
SILVA, R. B. da; DIAS DA SILVA, R. M. Democratização da gestão escolar no Estado do

Tocantins: uma análise crítica do Programa Escola Comunitária de Gestão Compartilhada

democratizantes. Nos termos de Norberto Bobbio, trata-se de uma relação interdependente e necessária, porque "é pouco provável que um estado não liberal possa assegurar um correto funcionamento da democracia e de outra parte é pouco provável que um estado não democrático seja capaz de garantir as liberdades fundamentais" (2006, p. 33).

Luiz Fernandes Dourado (2007), por sua vez, ao refletir sobre a qualidade e a gestão democrática da escola pública brasileira, oferece-nos uma abordagem qualificada sobre o cenário político e pedagógico à luz da gestão da educação básica, sustentada por fatores intra e extraescolares. Informa-nos o autor que:

a democratização dos processos de organização e gestão deve considerar as especificidades dos sistemas de ensino, bem como os graus progressivos de autonomia das unidades escolares a eles vinculados, e buscar a participação da sociedade civil organizada, especialmente o envolvimento de trabalhadores em educação, estudantes e pais (DOURADO, 2007, p. 925)

Considerar as especificidades dos sistemas de ensino é, por exemplo, conhecer as políticas públicas educacionais que visam à democratização, bem como as competências do Estado, enquanto ente regulador desses processos. Do mesmo modo, é oportuno compreender qual concepção de educação balizará - ponto de partida - aspectos importantes como a formação e o financiamento, correlacionados à gestão educacional, considerando em especial que "a escola, entendida como instituição social, tem sua lógica organizativa e suas finalidades demarcadas pelos fins político-pedagógicos que extrapolam o custo-benefício stricto sensu" (DOURADO, 2007, p. 924). Na prática, as limitações à atuação do Estado favorecem, o que afirmamos anteriormente, o fortalecimento da lógica empresarial na educação.

De acordo com Carvalho, há um novo modelo gerencial presente nos sistemas de ensino, no qual as escolas são pensadas em uma ambivalência entre a autonomia e a flexibilidade.

Na perspectiva, gerencial, a gestão autônoma do sistema educativo é concebida como capaz de gerar respostas adequadas à realidade de cada comunidade; é uma forma de assegurar a formação de uma identidade institucional e, ao mesmo tempo, o respeito à diversidade de interesses dos destinatários. Nesse sentido, a autonomia legitima a flexibilização organizacional do sistema, tornando-o capaz de assegurar uma diversificação/diferenciação da oferta, em face das diferentes necessidades e preferencias e de aumentar a rapidez das respostas em circunstâncias cambiantes e imprevistas. Como se pode observar na LDB n. 9394/96 que, diferentemente das legislações anteriores, dá ênfase à 
SILVA, R. B. da; DIAS DA SILVA, R. M. Democratização da gestão escolar no Estado do Tocantins: uma análise crítica do Programa Escola Comunitária de Gestão Compartilhada

descentralização, à autonomia das escolas e à participação da comunidade nos processos decisórios e flexibiliza a organização administrativa no interior das escolas (CARVALHO, 2009, p. 1155).

A flexibilização organizacional, neste caso, a escola flexível, atende aos princípios da administração pública gerencial, que se apresenta como uma oposição a formas rígidas e burocráticas de administrar. A escola flexível seria uma instituição condicionada por uma estrutura que concebe os processos de trabalho a indivíduos com autonomia, criatividade e conhecimento, cooperação, responsabilidade, capacidade para trabalhar em grupo e em equipes.

Para Richard Sennet, "a repulsa à rotina burocrática e a busca de flexibilidade produziram novas estruturas de poder e controle" (2000, p. 54). Para ele, há três elementos que dão subsídios para o sistema de poder: o primeiro é a "reinvenção descontínua de instituições" que, ancorada na mudança flexível, influencia também a mudança de comportamento, ou seja, uma reorganização que desconecta passado e presente, pautada pela eficiência e produtividade, reduzindo gastos, medindo resultados e modernizando a gestão administrativa; o segundo é a "especialização flexível" que visa atender a demanda de consumo, colocando variedades de produtos mais rapidamente no mercado; e por último "concentração de poder sem centralização" ao mesmo tempo que há a descentralização de poder, de maneira imperceptível, o poder hierárquico permanece por trás das ações descentralizadas, uma vez que "dá as pessoas mais controle sobre suas atividades, [...] cada unidade tem liberdade para cumprir da maneira que achar adequada" (SENNETT, 2000, p. 63). Na verdade, impõe um nível de produção além de suas capacidades e favorece o controle direto no trabalho, enfim uma falsa liberdade.

\section{Programa Escola Comunitária de Gestão Compartilhada no Tocantins: trajetória histórica}

Foi no apogeu da propagação de reformas neoliberais em escala internacional e influenciado por tal ideário, na década de 1990, que, no recém-emancipado estado do Tocantins, conjecturaram-se as políticas de educação visando sua primeira organização, estruturação e regulamentação. Um momento em que o cenário educacional desse novo estado da federação brasileira apresenta "alto índice de analfabetismo, crianças e jovens fora da sala de aula, má qualidade do ensino, formação inadequada dos professores, alto 
SILVA, R. B. da; DIAS DA SILVA, R. M. Democratização da gestão escolar no Estado do

Tocantins: uma análise crítica do Programa Escola Comunitária de Gestão Compartilhada

índice de evasão e repetência, precariedade da rede física escolar entre outros" (CARVALHO, 2004, p. 104).

No intuito de acelerar a evolução e o crescimento do estado, era preciso reverter esse cenário e superar tais problemas, o que mobilizou o governo do estado do Tocantins a planejar e adotar medidas para regulamentar e melhorar o processo de gestão da educação. Nesse sentido, foram elaborados e publicados, em 1992, o "Plano Estratégico Realidade e Perspectivas", o "Plano Decenal de Educação Para Todos" e o "Plano Estadual de Educação (1992-1995)”, enquanto respostas ao diagnóstico do precário cenário educacional do Estado. Propunham ações que efetivariam mudanças significativas, coadunando-se, posteriormente, à Lei de Diretrizes e Bases da Educação n. 9394/96 (LDB) que subsidiaria o Plano Estadual de Educação (1997 a 2006). Almejava-se, com efeito, "a universalização da educação, a autonomia da escola e melhorar a qualidade dos serviços educacionais" (CARVALHO, 2004, p. 114).

Nesse sentido, Carvalho descreve ainda que o referido Plano Estadual de Educação teve o objetivo de:

Implementar ações modernas $\mathrm{e}$ inovadoras que acompanhem o desenvolvimento tecnológico e as pesquisas; garantir racionalidade técnica e administrativa nos diversos setores da educação, assegurando competência, eficácia e eficiência; e promover a melhoria dos serviços educacionais, através de ações que agilizem respostas para as diferentes necessidades. Para atingir esses objetivos as estratégias estão direcionadas para a informatização do sistema educacional, adoção de meios corretivos no que se refere ao fluxo escolar (distorção idade/série); revisão curricular; adoção de mecanismos de combate à evasão e à repetência; atendimento às necessidades técnicas e administrativas ampliação e melhoria da rede física; aquisição de equipamentos e materiais de consumo e pedagógico; criação de sistema de comunicação; implantação de projetos e programas, oficinas, etc. - necessários ao desenvolvimento das ações educativas (CARVALHO, 2004, p. 95).

A gestão da educação no Tocantins, desde o PEE 1997-2006, desenvolveu ações de natureza "corretiva", as quais intencionavam a execução de estratégias que melhorassem o desenvolvimento das ações educativas e a consequente implantação de projetos e programas direcionados a diversos campos da ação educativa (CARVALHO, 2004). Assim, a Secretaria de Educação (SEDUC) traçou metas visando "universalizar a educação promovendo a autonomia das escolas com melhorias da qualidade de ensino e dos serviços educacionais" (NASCIMENTO, 2008, p. 71). A partir dessas metas, foi instituída uma concepção de gestão autônoma e compartilhada nas escolas públicas do estado do 
SILVA, R. B. da; DIAS DA SILVA, R. M. Democratização da gestão escolar no Estado do Tocantins: uma análise crítica do Programa Escola Comunitária de Gestão Compartilhada

Tocantins, fomentada já em 1995 com a criação da Associação de Apoio às Escolas (AAE), a qual assinalou que a comunidade deveria participar das tomadas de decisões. Para Carvalho, a SEDUC pretendia:

\begin{abstract}
Garantir a participação compartilhada dos pais, alunos, professores, funcionários e sociedade local na gestão da escola, tendo como foco o fornecimento às escolas de condições técnicas e financeiras para a resolução dos problemas de ordem administrativa e pedagógica. Neste sentido, as pessoas são envolvidas nas atividades escolares, tendo a AAE como instituição aglutinadora, interna e externa, dos indivíduos que participam da escola. Por meio de convênios firmados com a AAE, o governo descentraliza recursos e responsabilidades para as unidades escolares e sistematiza um processo de fiscalização e controle dos recursos centralizados na SEDUC (CARVALHO, 2004, p. 117 grifos nossos).
\end{abstract}

Em 1997, foi implantado o Programa Escola Autônoma de Gestão Compartilhada, inicialmente em 56 escolas e estendendo-se, no mesmo ano, para mais de 240. Em seus posicionamentos públicos, afirmava atender ao disposto na Lei de Diretrizes e Bases da Educação (LDB), especialmente em seus artigos 14 e 15.

\begin{abstract}
Art. 14. Os sistemas de ensino definirão as normas da gestão democrática do ensino público na educação básica, de acordo com as suas peculiaridades e conforme os seguintes princípios:

I - participação dos profissionais da educação na elaboração do projeto pedagógico da escola;

II - participação das comunidades escolar e local em conselhos escolares ou equivalentes.

Art. 15. Os sistemas de ensino assegurarão às unidades escolares públicas de educação básica que os integram progressivos graus de autonomia pedagógica e administrativa e de gestão financeira, observadas as normas gerais de direito financeiro público (BRASIL, 1996).
\end{abstract}

Entendeu-se que as bases desse programa de gestão democrática seriam autonomia escolar pedagógica, administrativa e financeira, cuja interpretação, no contexto, sinalizou para aspectos fundamentais para a efetivação da descentralização da tomada de decisões. Dessa maneira, passou a constar na Lei do Sistema Estadual de Educação do Estado do Tocantins, n. 1.038 de 1998, e a consolidar alguma consistência ou fundamentação político-administrativa:

Artigo 56. Instituições de ensino, respeitadas as normas comuns, terão a incumbência de:

I - elaborar e executar o Plano de ação Global e Projeto Político Pedagógico;

II - administrar seu pessoal e seus recursos materiais e financeiros; [...]

VI - articular-se com as famílias e a comunidade, criando processos de integração da sociedade com a escola; 
SILVA, R. B. da; DIAS DA SILVA, R. M. Democratização da gestão escolar no Estado do Tocantins: uma análise crítica do Programa Escola Comunitária de Gestão Compartilhada

VII - garantir a participação da Associação de Apoio à Escola no planejamento global e na aplicação de recursos financeiros;

VIII - prestar contas à Secretaria da Educação e Cultura da aplicação dos recursos recebidos através de programas de descentralização de recursos (TOCANTINS, 1998 grifos nossos).

Podemos observar que, para atender esses preceitos, a SEDUC deliberou que cada unidade escolar deveria seguir rigorosamente, por intermédio da AAE, os princípios de uma gestão democrática pautada pela melhoria da qualidade de ensino e pelo fortalecimento e pela participação da comunidade na escola. 0 instrumento utilizado foi o planejamento integrado, que nortearia a implantação e implementação da $\mathrm{AAE}$, principalmente para executar a descentralização de recursos. Observemos a figura abaixo, a qual demonstra o organograma operacional do programa e o posicionamento da AAE.

Figura 1 - Estrutura operacional do PECGC

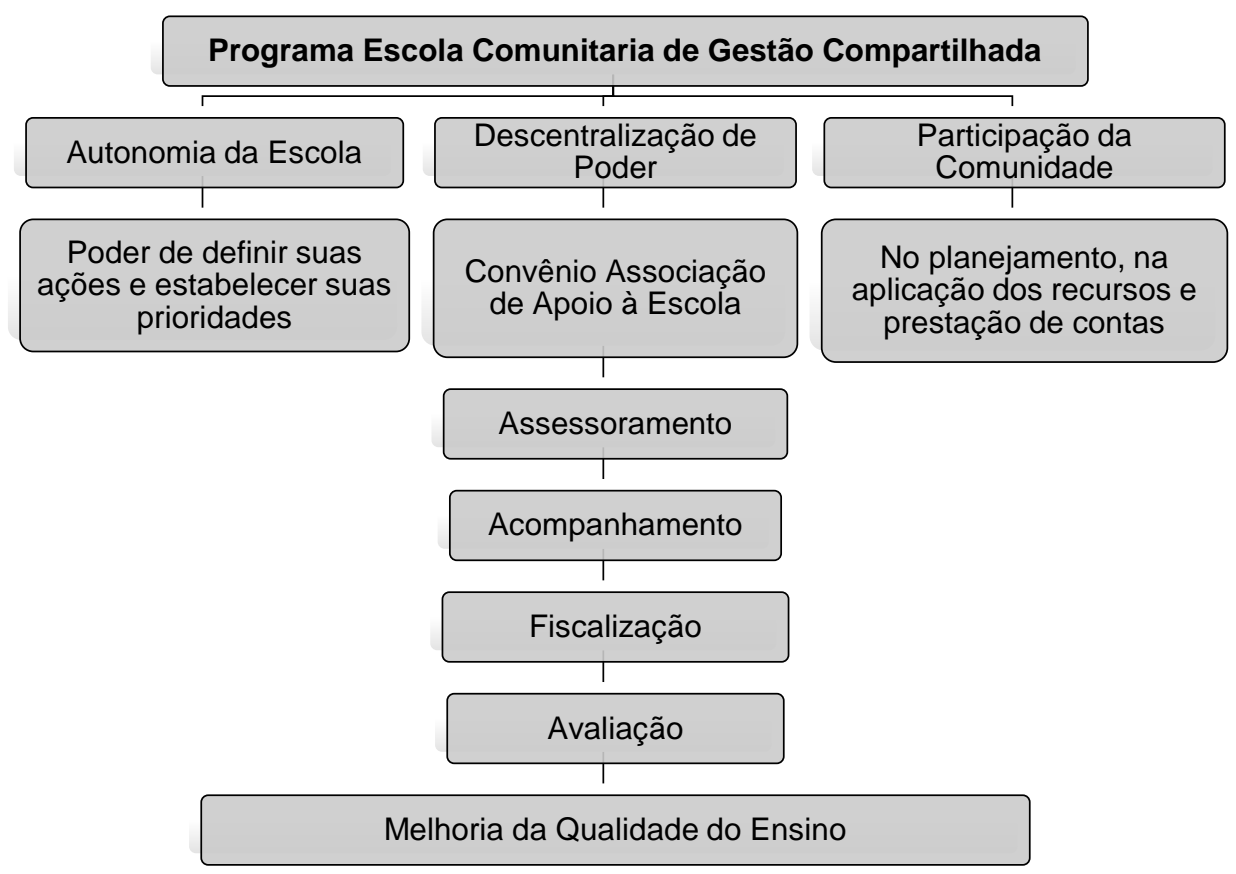

Fonte: CARVALHO, 2004, p.128.

A figura nos apresenta a tríade que sustenta o PECGC sendo, ao mesmo tempo, meta e ferramenta para a gestão democrática na escola: autonomia da escola, descentralização de poder e participação da comunidade. Chama-nos atenção o extensivo 
SILVA, R. B. da; DIAS DA SILVA, R. M. Democratização da gestão escolar no Estado do Tocantins: uma análise crítica do Programa Escola Comunitária de Gestão Compartilhada

papel da Associação de Apoio à Escola na operacionalização do programa, pois se até então as decisões estavam centradas na Seduc - na função de secretário - a partir de então, compete à escola tomar as decisões, mas somente se conveniada com AAE. É, portanto, uma relação de dependência com um órgão cuja incumbência é propositadamente inspecionar e controlar. Fato que, para Carvalho (2004), nesse caso, evidencia uma transposição de papéis na materialização das ações, em razão de haver a desconcentração de obrigações ao invés de descentralização de poder.

Em 2002, para dar ênfase à participação e à autonomia da comunidade, o programa passa a se chamar Escola Comunitária de Gestão Compartilhada. Nolêto (2009), ao realizar um estudo sobre a autonomia compartilhada da escola, afirma que essa autonomia se concretiza como princípio de gestão quando há "participação na tomada de decisões, fomentando a avaliação dos resultados e direcionando o olhar de todos os atores envolvidos nesse processo para o planejamento das ações, atividades e projetos a serem desenvolvidos pela escola" (NOLÊTO, 2009, p.4).

A autora demonstra-nos, ainda, que há uma associação entre autonomia e responsabilização, especificamente no que tange ao gerenciamento de recursos financeiros. Nolêto aponta que o:

\begin{abstract}
estado do Tocantins, através da Secretaria de Educação, oportuniza às escolas a autonomia assegurando que estes recursos sejam aplicados de acordo com as necessidades de cada unidade escolar, por acreditar no gerenciamento pelos gestores e na articulação destes com a Associação de Apoio. A autonomia pressupõe co-responsabilidade quando requer participação da comunidade na tomada de decisões pelos representantes de todos os segmentos da comunidade escolar: pais, alunos, professores e servidores administrativos, e assegura a democratização e autonomia para utilização dos recursos financeiros destinados a escola. (NOLÊTO, 2009, p. 5).
\end{abstract}

Segundo a autora, uma gestão autônoma pressupõe responsabilidade compartilhada com todos os envolvidos - aluno, professor, pais, comunidade, gestor - no desenvolvimento da escola, seja pela contribuição na manutenção ou pela participação e colaboração nos projetos educativos, bem como pelos resultados educacionais. Torna-se, no entanto, uma via de mão dupla, já que por um lado fortalece a efetivação da gestão democrática, por outro lado abre espaço para privatização, já que o Estado acaba se eximindo de certas responsabilidades e atuando somente como órgão regulador. 
SILVA, R. B. da; DIAS DA SILVA, R. M. Democratização da gestão escolar no Estado do

Tocantins: uma análise crítica do Programa Escola Comunitária de Gestão Compartilhada

\title{
Gestão escolar no Tocantins: efetivação e reestruturação
}

Mediante a intenção de contextualizarmos e compreendermos a política de democratização da educação no Tocantins, tomamos a análise documental como procedimento metodológico principal. Acreditamos que nos possibilitará apreender elementos significativos da construção social e histórica dessa política, bem como os movimentos e processos de efetivação e reestruturação do PECGC. Para tal, identificamos, verificamos e analisamos dez documentos institucionais produzidos pela Secretaria Estadual de Educação do Tocantins (SEDUC) no período de 1997 a 2017, os quais constam abaixo no Quadro 1. A seleção desse recorte temporal corresponde, respectivamente, ao ano de criação ou constituição das primeiras iniciativas do programa político até o ano de sua última e mais atual reestruturação.

Ao revisitar os documentos oficiais que orientam e regulam as práticas e ações do gerenciamento educacional no Estado, é possível identificarmos como as mudanças, no intuito de conceber a descentralização e democratização da gestão escolar, têm sido conectadas com a lógica empresarial, da "qualidade total" e de seus princípios, a saber: a gerência participativa, delegação de responsabilidades, aperfeiçoamento contínuo, gerência de processos e a garantia da qualidade.

Para Longo, esses princípios são aplicados na organização da escola da seguinte forma:

\begin{abstract}
foco centrado em seu principal cliente - o aluno; forte liderança dos dirigentes; visão estratégica (valores, missão e objetivos) claramente definida e disseminada; plano político pedagógico oriundo de sua visão estratégica e definido pelo consenso de sua equipe de trabalho, clima positivo de expectativa quanto ao sucesso; forte espírito de equipe; equipe de trabalho consciente do papel que desempenha na organização de suas atribuições; equipe de trabalho capacitada e treinada para melhor desempenhar suas atividades; planejamento, acompanhamento e avaliação sistemáticos dos processos; e preocupação constante com inovações e mudanças (LONGO, 1996, p. 13-14).
\end{abstract}

Em síntese, o foco seria adequar a estrutura organizacional da escola aos moldes do gerencialismo e, assim, melhorar com eficiência e eficácia a qualidade da educação. É o que constatamos no Programa Escola Comunitária de Gestão Compartilhada, o qual propõe a democratização da educação no estado do Tocantins, por meio de uma gestão escolar autônoma e descentralizada. Observemos, no Quadro 1, a descrição de alguns 
aspectos citados nos dez documentos analisados, circunscritos à temporalidade delimitada acima.

Quadro 1 - Descrição dos Aspectos da Gestão Democrática

\begin{tabular}{|c|c|c|}
\hline DOCUMENTO & ANO & GESTÃO DEMOCRÁTICA \\
\hline $\begin{array}{l}\text { Administração } \\
\text { e Gestão } \\
\text { Compartilhada } \\
\text { das Escolas } \\
\text { Públicas } \\
\text { Estaduais }\end{array}$ & 1997 & $\begin{array}{l}\text { O estabelecimento de uma nova sistemática de } \\
\text { administração e de gestão compartilhada objetiva } \\
\text { garantir autonomia e gestão democrática para a } \\
\text { construção de um projeto pedagógico, com a } \\
\text { participação e envolvimento de todos os profissionais } \\
\text { que atuam na escola e na comunidade. }\end{array}$ \\
\hline $\begin{array}{l}\text { Orientações } \\
\text { gerais para } \\
\text { elaboração do } \\
\text { Projeto Político } \\
\text { Pedagógico }\end{array}$ & 1998 & $\begin{array}{l}\text { É delegar competências: é o diretor deixar de ser } \\
\text { autoridade única da escola e também deixar de ser } \\
\text { aquele administrador burocrático, preocupado apenas } \\
\text { com a manutenção do prédio, com preenchimento de } \\
\text { papeis e suprimento de recursos materiais e humanos. } \\
\text { Passando a ser o grande articulador das ações de todo os } \\
\text { segmentos, o condutor do projeto da escola, aquele que } \\
\text { prioriza as questões pedagógicas e que mantém o ânimo } \\
\text { de todos na construção do trabalho educativo. }\end{array}$ \\
\hline $\begin{array}{l}\text { Regimento } \\
\text { Escolar }\end{array}$ & 2005 & $\begin{array}{l}\text { Apresenta-se ele constituído do conjunto de normas, } \\
\text { diretrizes, estrutura e funcionamento das ações } \\
\text { escolares, para garantir o uso racional dos recursos } \\
\text { materiais e humanos e assegurar a legitimidade das } \\
\text { decisões tomadas no âmbito da gestão escolar. }\end{array}$ \\
\hline $\begin{array}{ll}\text { Orientações } & \\
\text { para } & \text { as } \\
\text { Associações } & \text { de } \\
\text { Apoio } & \text { às } \\
\text { Escolas. } & \end{array}$ & 2006 & $\begin{array}{l}\text { A participação efetiva da comunidade no processo } \\
\text { educacional e autonomia progressiva da escola são } \\
\text { indispensáveis para a consolidação de um ensino de } \\
\text { qualidade para todos. Dessa forma, o Governo do Estado } \\
\text { vem preocupando-se com a descentralização da gestão e } \\
\text { com a participação da sociedade civil nas políticas } \\
\text { públicas. }\end{array}$ \\
\hline $\begin{array}{l}\text { Programa } \\
\text { Escola } \\
\text { Comunitária de } \\
\text { Gestão } \\
\text { Compartilhada }\end{array}$ & 2007 & $\begin{array}{l}\text { A descentralização de recursos financeiros garante a } \\
\text { autonomia pedagógica, administrativa e financeira das } \\
\text { Unidades Escolares que está diretamente vinculada a um } \\
\text { processo de prestação de contas à comunidade, dos } \\
\text { investimentos recebidos, em termos de resultados } \\
\text { expressos pela aprendizagem dos alunos. O estado } \\
\text { repassa os recursos, assessora e fiscaliza; a comunidade } \\
\text { escolar planeja, avalia e executa. Espera-se que a } \\
\text { interação do poder público com a comunidade escolar } \\
\text { alcance os objetivos do trabalho educativo no que diz } \\
\text { respeito à democratização e a melhoria da qualidade do } \\
\text { ensino. }\end{array}$ \\
\hline $\begin{array}{l}\text { Regimento } \\
\text { Escolar }\end{array}$ & 2011 & $\begin{array}{l}\text { Estabelece um conjunto de regras que determinam a } \\
\text { organização administrativa, didática, pedagógica, }\end{array}$ \\
\hline
\end{tabular}


SILVA, R. B. da; DIAS DA SILVA, R. M. Democratização da gestão escolar no Estado do Tocantins: uma análise crítica do Programa Escola Comunitária de Gestão Compartilhada

\begin{tabular}{|c|c|c|}
\hline & & $\begin{array}{l}\text { disciplinar; (...) O documento foi reformulado por uma } \\
\text { comissão de trabalho composta de representantes dos } \\
\text { diversos segmentos do contexto educacional; } \\
\text { garantindo, assim um olhar efetivamente voltado para o } \\
\text { processo de consolidação da gestão democrática do } \\
\text { ensino e da autonomia administrativa e pedagógica da } \\
\text { escola. }\end{array}$ \\
\hline $\begin{array}{l}\text { Manual do } \\
\text { Sistema de } \\
\text { Transparência } \\
\text { da Secretaria } \\
\text { Estadual de } \\
\text { Educação e } \\
\text { Cultura } \\
\end{array}$ & 2013 & $\begin{array}{l}\text { Tem como objetivo orientar, de um modo rápido e } \\
\text { simples, o cidadão e os agentes públicos a encontrarem } \\
\text { as informações desejadas para conhecer a aplicação dos } \\
\text { recursos públicos Federais e Estaduais contribuindo com } \\
\text { o Governo em seu papel de provedor e fiscalizador dos } \\
\text { recursos descentralizados, através do Programa "Escola } \\
\text { Autônoma de Gestão Compartilhada". }\end{array}$ \\
\hline $\begin{array}{l}\text { Regimento } \\
\text { Escolar }\end{array}$ & 2017 & $\begin{array}{l}\text { Com o objetivo de proporcionar uma educação de } \\
\text { qualidade para todos, com a garantia do acesso, } \\
\text { atendimento, permanência e sucesso na aprendizagem } \\
\text { dos alunos, o documento contempla os princípios de } \\
\text { gestão e normatização do funcionamento das unidades } \\
\text { escolares estaduais referentes à estrutura } \\
\text { administrativa, à oferta dos níveis e modalidades de } \\
\text { ensino previsto, à organização e registro da vida escolar } \\
\text { dos alunos... }\end{array}$ \\
\hline $\begin{array}{l}\text { Programa } \\
\text { Escola } \\
\text { Comunitária de } \\
\text { Gestão } \\
\text { Compartilhada } \\
\text { - Educação de } \\
\text { qualidade para } \\
\text { todos. }\end{array}$ & 2017 & $\begin{array}{l}\text { O PECGC tem como objetivo democratizar a gestão } \\
\text { educacional, visando dar agilidade e autonomia para } \\
\text { elaborar, implementar e fortalecer o Projeto Político } \\
\text { Pedagógico (...) fundamenta-se na participação efetiva } \\
\text { da comunidade escolar e local no processo educativo, na } \\
\text { responsabilidade social, na descentralização dos } \\
\text { recursos públicos e na autonomia, visando à melhoria da } \\
\text { qualidade do ensino, expressa pelo sucesso do aluno na } \\
\text { sua formação acadêmica. }\end{array}$ \\
\hline Folder PECGC & 2017 & $\begin{array}{l}\text { O PECGC foi reestruturado contemplando projetos e } \\
\text { ações voltados para a consolidação de uma educação de } \\
\text { qualidade, levando em consideração, a participação da } \\
\text { comunidade escolar e local no planejamento e nas } \\
\text { tomadas de decisões. }\end{array}$ \\
\hline
\end{tabular}

Fonte: Elaborado pelos autores

O quadro apresenta excertos documentais que caracterizam a gestão democrática proposta pelo PECGC, com evidência aos sentidos de democratização em articulação à qualidade educacional e de participação social. No exercício de seleção e análise, foi possível identificar alguns conceitos-chave que evidenciam o que significam as ações e projetos desenvolvidos: autonomia, delegação de responsabilidade, tomada de decisões, 
SILVA, R. B. da; DIAS DA SILVA, R. M. Democratização da gestão escolar no Estado do Tocantins: uma análise crítica do Programa Escola Comunitária de Gestão Compartilhada

descentralização da gestão e de recursos financeiros. O conjunto desses descritores, no panorama social mais amplo comentado nas seções anteriores, evidencia uma significativa inclinação dessa política ao reconhecimento da pertinência pública da participação dos atores no controle e na condução das políticas públicas e, de algum modo, seu ambíguo protagonismo na definição mais consistente de ações direcionadas à qualificação das experiências escolares. Seguramente, participação e qualidade são princípios caros à democratização das políticas educacionais, contudo importa destacar que, uma vez que possuem uma semântica plural, seus sentidos precisam ser examinados e problematizados.

Outro elemento que foi percebido nos documentos analisados e explicitado nos dois últimos documentos, no contexto da reestruturação do programa, é a articulação entre educação e qualidade. Evidencia-se que o processo de democratização da gestão deverá efetuar melhorias na qualidade de ensino, enunciado pelo sucesso do aluno, ou seja, focaliza a gestão democrática como ponte que justifica ações e processos formativos, pelo viés da padronização. Há, como os fragmentos demonstram, uma definição simplificada de qualidade, interpretada enquanto sinônimo ou decorrência de "bons resultados".

Convém ressaltarmos que esses documentos foram produzidos pela Secretaria Estadual de Educação do Tocantins com o objetivo de se constituírem em "guias" ou materiais instrucionais, compondo-se e sendo reproduzidos sob a forma de manuais, normas, cartilhas e regimentos, a serem seguidos pela comunidade escolar - gestores, professores, funcionários, alunos e pais. Enquanto política educacional, o Programa Escola Comunitária de Gestão Compartilhada concebe a escola como uma organização constituída por pessoas que se mobilizam para alcançar seus objetivos (da organização), ou seja, uma organização direcionada racionalmente à consecução de resultados. Nesse sentido, a gestão tem como concepção o regime político democrático participativo, que reflete principalmente a participação, o que, discursivamente, tende a acentuar um "estado de ambivalência".

Para Libâneo, Oliveira e Toschi, a concepção democrático participativa

Acentua a necessidade de combinar a ênfase sobre as relações humanas e sobre a participação das decisões com as ações efetivas para atingir com êxito os objetivos específicos da escola. Por isso, valoriza elementos internos do processo organizacional - o planejamento, a organização, a direção, a avaliação [...] $a$ 
SILVA, R. B. da; DIAS DA SILVA, R. M. Democratização da gestão escolar no Estado do Tocantins: uma análise crítica do Programa Escola Comunitária de Gestão Compartilhada

gestão democrática, por um lado, é atividade coletiva que implica a participação e objetivos comuns; por outro, depende também de capacidades e responsabilidades individuais e de uma ação coordenada e controlada. (LIBÂNEO; OLIVEIRA; TOSCHI; p. 326, 2008 grifos nossos).

Percebemos, portanto, como as pessoas, nesse processo de organização e gestão escolar, são consideradas recursos essenciais, cujas relações são interpretadas como condições também essenciais na implantação da democratização da gestão escolar. Seguidamente correlacionado à participação, interpretada como fundamental para a autonomia escolar, outro princípio disposto por esse programa é o compartilhamento na tomada de decisões e na execução de tarefas, assim como o papel do gestor na coordenação deste processo democrático. Em sua documentação, o PECGC defende que uma gestão descentralizada amplamente contribui para melhoria dos resultados educacionais, ou seja, uma escola democrática é sinônimo de educação pública de qualidade para todos.

Com o slogan “Educação de Qualidade para Todos”, em 2017, após quase vinte anos de implantação, o governo do Tocantins por meio da Secretaria de Educação e Cultura reestruturou novamente o Programa Escola Comunitária de Gestão Compartilhada. Essa reestruturação, de acordo com o documento orientador, visa:

oferecer os serviços necessários ao desenvolvimento eficaz do processo ensino e aprendizagem, garantindo o acesso, o atendimento e a permanência com sucesso do aluno na escola. 0 programa revitaliza as ações da gestão escolar com foco no aluno e na sua aprendizagem. Sendo o professor o ator principal deste processo educativo. [...] Para apoiar a gestão escolar, nesta reestruturação do programa, foram contemplados aumento da per capita aluno, projetos pedagógicos que valorizam a participação dos professores, pais e alunos nas decisões, nos compromissos e nas responsabilidades, empoderando os envolvidos no processo educativo para a melhoria dos resultados educacionais. (TOCANTINS, p. 3, 2017 grifos nossos).

Podemos observar que em busca de melhoria dos resultados educacionais há uma reafirmação das responsabilidades. Em destaque, citamos o papel do professor, que conforme consta no documento de 2017, assume o compromisso de garantir o sucesso e a permanência do aluno na escola. 0 professor se vê tão imerso nessa lógica gerencialista e neoliberal que acaba naturalizando algumas ações e atitudes frente à sua função. A esse respeito, Ball nos apresenta o conceito de performatividade:

De fato, a performatividade é a forma por excelência de governamentalidade neoliberal, que abrange a subjetividade, as práticas institucionais, a economia e 
SILVA, R. B. da; DIAS DA SILVA, R. M. Democratização da gestão escolar no Estado do Tocantins: uma análise crítica do Programa Escola Comunitária de Gestão Compartilhada

o governo. É tanto individualizante quanto totalizante. Ela produz docilidade ativa e produtividade sem profundidade. A performatividade convida-nos e incita-nos a tornarmo-nos mais efetivos, a trabalharmos em relação a nós mesmos, a melhorarmos a nós mesmos e a sentirmo-nos culpados ou inadequados se não o fizermos. [...] A performatividade "funciona" mais poderosamente quando está dentro de nossas cabeças e de nossas almas. Ou seja, quando nós a aplicamos em nós mesmos, quando assumimos responsabilidade de trabalhar duro, mais rápido e melhor, assim "melhoramos" nossa "produção" como parte de nossa autovalorização e valorização dos outros (BALL, 2014, p.66).

As relações de poder que circunscrevem a "subjetividade dos praticantes" vão muito além dos deveres estabelecidos aos docentes pela LDB no artigo 13. Trata-se de uma força ideológica impregnada por um discurso em prol da eficácia, que corrobora com a inserção de concepções mercadológicas (gerencialismo) dentro da escola: desempenho, eficiência e empreendedorismo. Assim, “indivíduo autogerenciado e a organização autônoma são produzidos dentro dos interstícios da performatividade por meio de auditorias, inspeções, avaliações, autorrevisões, garantia de qualidade, avaliações de pesquisa, indicadores de resultados e assim por diante" (BALL, 2014, p.67).

Na prática escolar, essa performatividade (BALL, 2014) apresenta-se de diferentes maneiras. Há, por exemplo, um contrato - termo de compromisso - firmado em 2011 entre a Secretaria Estadual de Educação e as escolas (gestor escolar) que trata das obrigações normativas para uma gestão eficaz:

1. Garantir a qualidade social da educação promovendo o desenvolvimento integral dos alunos, visando atingir o índice da educação básica - IDEB de 5,0 pontos nas séries iniciais, 4,5 pontos nas séries finais do ensino fundamental e 4,0 no ensino médio, em 2011;

2. Reduzir em $50 \%$ os índices de abandono, evasão, distorção idade/série e reprovação dos alunos em todas as séries ofertadas pela escola;

3. Programar a alimentação escolar nos 200 dias letivos com aquisição de pelo menos 30\% da alimentação escolar da Agricultura Familiar;

4. Superar as metas do IDEB até 2015;

5. Apresentar propostas de Padrões Mínimos Educacionais para a Unidade Escolar;

6. Promover o desenvolvimento das habilidades de letramento e garantir a alfabetização de Jovens e Adultos;

7. Garantir a uniformização da comunidade escolar;

8. Realizar semestralmente uma audiência pública para prestação de contas dos recursos financeiros da escola;

9. Apresentar e desenvolver projetos e/ou ações de combate ao bullying na escola;

10. Estabelecer a unidade e integração das ações da Unidade Escolar com foco no resultado da formação e aprendizagem dos alunos em conformidade com as 10 (dez) dimensões da Gestão Escolar;

11. Promover a aplicação de avaliação institucional e outras atividades inerentes; 
SILVA, R. B. da; DIAS DA SILVA, R. M. Democratização da gestão escolar no Estado do Tocantins: uma análise crítica do Programa Escola Comunitária de Gestão Compartilhada

12. Oportunizar a participação dos professores e demais servidores nas
formaçães continuadas, fóruns e similares;
13 . Garantir a integralização do currículo escolar com o mínimo de 200 dias
letivos e 800 horas anuais;
$14 . \quad$ Monitorar a frequência dos servidores escolares garantindo-se a
reposição de aulas quando da infrequência justificada e assegurar o
cumprimento do regimento escolar;
15 Cumprir e fazer cumprir todas as normas do Sistema Estadual de
Educação (PPP/EES. 2011, p. 25-26).

Essas normativas tornaram-se compromissos e foram divulgadas e cumpridas na escola. No que tange ao currículo, há parcerias firmadas com organizações privadas como o Instituto Ayrton Senna, por meio dos programas Se Liga e Acelera Brasil. A parceria é regulamentada pela Instrução Normativa n. 12, de 28 de fevereiro de 2005, e justificada pela ênfase no "sucesso do aluno e a correção do fluxo escolar" (SEDUC, 2005, art. 1).

No entendimento da SEDUC, o PECGC é um programa que muda a estrutura do gerenciamento da educação, em que as responsabilidades são compartilhadas entre governo, profissionais da educação e comunidade (TOCANTINS, 2017, p. 6). Dessa forma, sua operacionalização responde aos anseios desse novo reordenamento, a começar pela Associação de Apoio à Escola/Conselho Educacional, meio pelo qual é garantida a efetiva participação da comunidade, o qual também direciona a construção de uma "rede de responsabilidade e aprendizado mútuo capaz de promover a melhoria da qualidade do ensino, propiciando uma cultura pedagógica sólida e fundamental para promoção do direito à educação" (TOCANTINS, 2017, p. 10). A descentralização dos recursos financeiros também está relacionada à melhoria dos resultados de aprendizagem dos alunos, com a base de cálculos, os quais reestruturam o nivelamento de valores destinados à escola conforme o Censo Escolar do ano anterior. São incluídos recursos para manutenção da escola e descentralização de obras.

Quanto aos Projetos de Ensino-Aprendizagem (PEA), estes terão os recursos disponíveis de acordo com o resultado do Índice de Desenvolvimento da Educação Básica, se o resultado for baixo, os projetos serão executados com "o propósito de fortalecer a prática pedagógica, promovendo melhorias significativas à aprendizagem e ao desenvolvimento dos estudantes" (TOCANTINS, 2017, p. 13).

O PECGC é, em sua essência, uma política educacional que visa democratizar a gestão, juridicamente relacionado à Constituição Federal (art. 206), à Lei de Diretrizes e Bases da Educação (art. 203) e ao Plano Nacional de Educação (2014-2024). No contexto das escolas, sua materialização é um desafio posto às escolas e a todos os seus segmentos, 
SILVA, R. B. da; DIAS DA SILVA, R. M. Democratização da gestão escolar no Estado do Tocantins: uma análise crítica do Programa Escola Comunitária de Gestão Compartilhada

nomeadamente: (a) efetivar e garantir de fato uma gestão trilhada pela democracia; e (b) gerir o público por meio de pressupostos democráticos.

\section{Considerações analíticas}

O objetivo do presente texto foi analisar de que forma o Programa Escola Comunitária de Gestão Compartilhada contribui para a democratização da educação no Tocantins. Analisamos os princípios que fundamentam e dão base à gestão democrática na escola, a saber: autonomia pedagógica, administrativa e financeira; e delegação de competências e responsabilidades na busca de uma educação de qualidade para todos.

As políticas públicas em prol da gestão democrática operam a partir do discurso do compartilhamento de decisões, relacionando racionalização e participação. Por outro lado, nesse mesmo contexto, as escolas públicas são submetidas à lógica de mercado, imperando, em suas práticas de gestão, o empresariamento da educação e a responsabilização dos atores escolares pelos resultados obtidos.

Ao realizar esse exercício analítico, percebeu-se que as diretrizes do PECGC autonomia, descentralização e responsabilidade social - regulam a organização e estruturação da escola. A construção coletiva do Projeto Político Pedagógico é uma das ações que fortalece a escola política e pedagogicamente, visto que por meio desse documento se evidencia a identidade e autonomia escolar, bem como a descentralização dos recursos financeiros está relacionada à melhoria dos resultados de aprendizagem dos alunos.

Nesse contexto, a aferição dos resultados classifica as escolas e, de forma desigual, determina o nível de recursos e benefícios a serem recebidos. Além disso, em se tratando de baixo rendimento, há a culpabilização da própria escola e de seus atores. Há, portanto, a propagação de uma cultura da responsabilização chamada de "rede de responsabilidade", a qual, nos termos desses modelos de gestão, tem a capacidade de melhorar a qualidade do ensino.

Conclui-se haver uma ambivalência entre a propagação de uma cultura da responsabilização, chamada de "rede de responsabilidade", e a efetivação de uma gestão democrática, interpretada enquanto ação coletiva que precisa ser vivenciada continuamente a partir do aprendizado da democracia. Tal ambivalência evidencia a 
SILVA, R. B. da; DIAS DA SILVA, R. M. Democratização da gestão escolar no Estado do Tocantins: uma análise crítica do Programa Escola Comunitária de Gestão Compartilhada

pertinência de problematizações acerca das definições de democracia e de gestão democrática no bojo dessa política.

\section{Referências}

AFONSO, A. J. Reforma do Estado e políticas educacionais: entre a crise do estado-nação e a emergência da regulação supranacional. Educação \& Sociedade, n.75, p. 15-32, 2001.

BALL, STEPHEN J. Educação Global S.A Novas redes políticas e o imaginário neoliberal. Ponta Grossa: UEPG, 2014.

BALL, STEPHEN J.\& JEFFERSON, MAINARDES (Org.). Políticas Educacionais: Questões e Dilemas. SÃO PAULO: CORTEZ, 2011, 288 p.

BARROSO, João. Relatório da disciplina "Teoria das Organizações e da Administração Educacional". Lisboa: Faculdade de Psicologia e Ciências da Educação da Universidade de Lisboa, 2001.

BOBBIO, Norberto. O futuro da democracia. São Paulo: Paz e Terra. 2006.

BRASIL. MEC. Lei de Diretrizes e Bases da Educação Nacional. n. 9394/1996.

CARVALHO, E. J. G. . Autonomia da gestão escolar: uma relação entre a política de democratização e privatização da educação. Teoria e Prática da Educação , v. 11, p. 265$274,2008$.

CARVALHO, E. J. G. Reestruturação produtiva, reforma administrativa do Estado e gestão da educação. Educação e sociedade, Campinas, v. 30, n. 109, p. 1139-1166, set./dez. 2009.

CARVALHO, Roberto Francisco de. A gestão da educação básica no Tocantins: concepção e lógica do programa escola autônoma de gestão compartilhada. 2004. Dissertação (Mestrado em Educação) - Universidade Federal de Goiás - UFG/ Faculdade de educação. Goiânia, GO.

CURY, C. R. J. O Conselho Nacional de Educação e a Gestão Democrática. In: OLIVEIRA, Dalila Andrade (Org.). Gestão democrática da educação: desafios contemporâneos. Petrópolis, RJ: Vozes, 1997. p. 199-245.

CURY, Carlos robertoJamil. Gestão Democrática da Educação: Exigencias e Desafios. RBPAE v.18, n.2,jul./dez. 2002.

DALE, R. Globalização e educação: demonstrando a existência de uma "cultura educacional mundial comum" ou localizando uma "agenda globalmente estruturada para a educação". Educação \& Sociedade, v. 25, n. 87, p. 423-460, 2004. 
SILVA, R. B. da; DIAS DA SILVA, R. M. Democratização da gestão escolar no Estado do Tocantins: uma análise crítica do Programa Escola Comunitária de Gestão Compartilhada

DOURADO, Luiz Fernandes. Políticas e Gestão da Educação Básica no Brasil: Limites e Perspectiva. Educ. Soc., Campinas, Vol. 28, N. 100 - Especial, P. 921-946, Out. 2007.

DRABACH, N.; MOUSQUER, M. E. Dos primeiros escritos sobre administração escolar no Brasil aos escritos sobre gestão escolar: mudanças e continuidades. Currículo sem fronteiras, v. 9, n. 2, p. 258-285, 2009.

LIBÂNEO, J. C. O dualismo perverso da escola pública brasileira: escola do conhecimento para os ricos e escola do acolhimento social para os pobres. Educação e Pesquisa, v. 38, n. 1, p. 13-28, 2012.

LONGO, Rose Mary Juliano. Gestão da Qualidade: Evolução Histórica, Conceitos Básicos e Aplicação na Educação. Brasília, 1996. Disponível em:

http://www.ipea.gov.br/pub/td/td_397.pdf. Acesso em: 02 ago.2009.

LUDKE, Menga; ANDRE, Marli. A pesquisa em educação: abordagens qualitativas. São Paulo: EPU, 1986.

NASCIMENTO, Maurício Reis Sousa do. O Programa Escola Comunitária de Gestão Compartilhada: Descentralização ou desconcentração nas escolas públicas estaduais de Miracema do Tocantins. 2008. Dissertação (Mestrado em Educação) - Universidade Federal de Uberlândia- UFU/ Faculdade de Educação. Uberlândia, MG.

NOLÊTO, Eusébia de Araújo Pereira. Gestão compartilhada: autonomia da escola. II Congresso Consad de Gestão Pública - Painel 16: Gestão de Políticas Públicas em Educação, 2009.

PARO, Vitor Henrique. Administração escolar: introdução crítica. São Paulo: Cortez/Autores Associados, 2001.

PARO, Vitor Henrique. Eleição de diretores: a escola pública experimenta a democracia. Campinas, SP: Papirus, 1996.

SENNETT, R. A corrosão do caráter: consequências pessoais do trabalhador no novo capitalismo. 4. ed. Rio de Janeiro: Record, 2000.

TOCANTINS. Programa Escola Comunitária de Gestão compartilhada. Seduc, Palmas, 2007.

TOCANTINS. Secretaria de Educação, Juventude e Esportes. Escola Comunitária de Gestão Compartilhada: Educação de Qualidade para Todos. 2017.

TOCANTINS. Secretaria Estadual de Educação. Administração e Gestão Compartilhada das Escolas Públicas Estaduais. Palmas, Seduc, 1997.

TOCANTINS. Secretaria Estadual de Educação. Orientações gerais para elaboração do Projeto Político Pedagógico. Palmas, Seduc, 1998. 
SILVA, R. B. da; DIAS DA SILVA, R. M. Democratização da gestão escolar no Estado do Tocantins: uma análise crítica do Programa Escola Comunitária de Gestão Compartilhada

TOCANTINS, Secretaria de Estado da Educação e Cultura. Instrução Normativa n.12 para os Programas Se Liga e Acelera Tocantins. TO: SEDUC, 2005. 
SILVA, R. B. da; DIAS DA SILVA, R. M. Democratização da gestão escolar no Estado do

Tocantins: uma análise crítica do Programa Escola Comunitária de Gestão Compartilhada

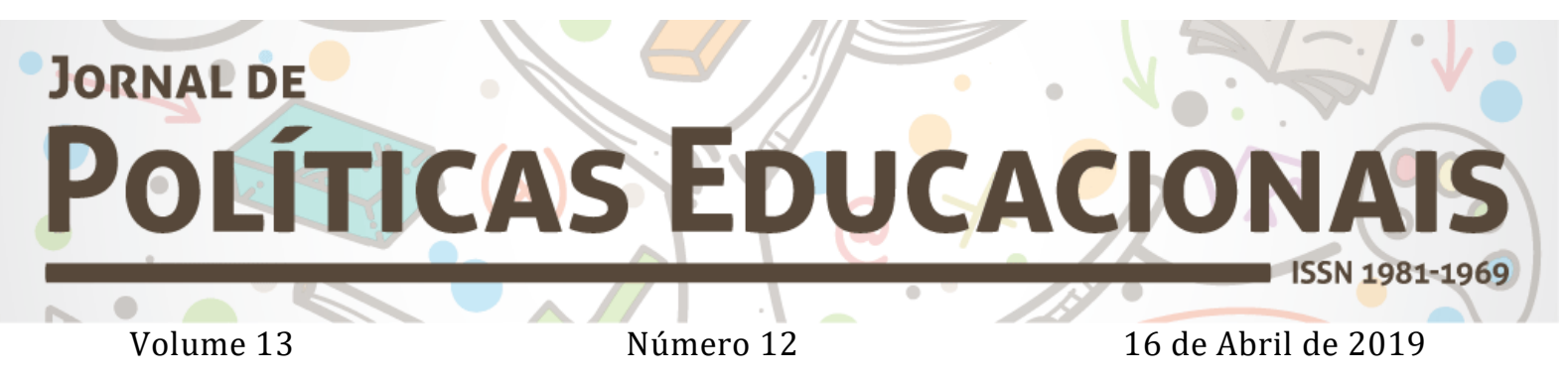

(c)

SOCRERIGHIS RESERVED O Copyright é retido pelo/a autor/a (ou primeiro co-autor) que outorga o direito da primeira publicação ao Jornal de Políticas Educacionais. Mais informação da licença de CreativeCommons encontram-se em http://creativecommons.org/licenses/by-nc-nd/2.5. Qualquer outro uso deve ser aprovado em conjunto pelo/s autor/es e pelo periódico.

JoRnal DE Políticas EdUCACIONAIS é uma publicação do Núcleo de PolíticasEducacionaisdo Setor de Educação da Universidade Federal do Paraná - NuPE/UFPR, em consórcio com a Linha de Pesquisa em Políticas Educacionais do Programa de Pós-Graduação em Educação - PPGE/UFPR, que aceita colaboração, reservando-se o direito de publicar ou não o material espontaneamente enviado à redação. As colaborações devem ser enviadas ao NuPE/UFPR, conforme orientações contidas nas páginas do periódico na internet: http://revistas.ufpr.br/ipe.

\author{
Indexação: \\ BBE - Biblioteca Brasileira de Educação (MEC/INEP) \\ Clase (Base de Datos Bibliográfica de Revistas de Ciencias Sociales y Humanidades) \\ Diadorim - Diretório de Política de Acesso Aberto das Revistas Científicas Brasileiras (IBICT) \\ Google Scholar \\ Index Copernicus \\ Portal de Periódicos (CAPES) \\ SER - Sistema Eletrônico de Revistas da Universidade Federal do Paraná (SER/UFPR) \\ Sumários de Revistas Brasileiras (FUNPEC-RP) \\ DRJI - Directory of Research Journals Indexing
}

(Periódico integralmente disponível apenas em via eletrônica)

Jornal de Políticas Educacionais / Núcleo de Políticas Educacionais da Universidade Federal do Paraná NuPE/UFPR - v.1, n. 1 (1o semestre de 2007) - Curitiba: NuPE/UFPR.

Volume 13, número 12 - Abril de 2019

ISSN 1981-1969

1. Educação - Periódicos. 2. Política Educacional - Periódicos. I. NuPE/UFPR

Comitê Editorial:

Elisângela Scaff (UFPR)

Daniela de Oliveira Pires (UFPR)

Ana Lorena Bruel (UFPR)

Conselho Editorial:

Andréa Barbosa Gouveia (UFPR), Ângela Hidalgo (UNICENTRO), Cesar GernominoTello (Universidad Nacional TresFebrero, Argentina),Gladys Beatriz Barreyro (USP), Juca Gil (UFRGS), Jefferson Mainardes 
SILVA, R. B. da; DIAS DA SILVA, R. M. Democratização da gestão escolar no Estado do Tocantins: uma análise crítica do Programa Escola Comunitária de Gestão Compartilhada

(UEPG), João Ferreira de Oliveira (UFG), Luiz Souza Júnior (UFPB), Marcos Edgard Bassi (UFSC), Regina Maria Michelotto (UFPR), Robert Verhine (UFBA), Rosana Cruz (UFPI), Rubens Barbosa Camargo (USP), Sebastián Donoso Díaz (Universidad de Talca, Chile), Taís Moura Tavares (UFPR), Theresa Adrião (UNICAMP), Vera Peroni (UFRGS).

Créditos e Agradecimentos:

Revisão de Língua Portuguesa, Abstract e Resumen: PROGRAMA DE APOIO ÀS PUBLICAÇÕES CIENTÍFICAS PERIÓDICAS DA UFPR

Arte e diagramação: TIAGO TAVARES (tiagotav@gmail.com)

Jornal de Políticas Educacionais

Universidade Federal do Paraná

Setor de Educação

Núcleo de Políticas Educacionais - NuPE/UFPR

Avenida Sete de Setembro, 2645

$2^{\circ}$ andar, Sala 213

80.230-010 - Curitiba - PR - Brasil

Tel.: 41-3535-6264

jpe@ufpr.br

http://revistas.ufpr.br/jpe 